\title{
Observations of corrosion pits and cracks in corrosion fatigue of high strength aluminum alloy by computed-tomography using synchrotron radiation
}

\author{
Y. Nakai ${ }^{1, a}$, and D. Shiozawa ${ }^{1}$ \\ ${ }^{1}$ Department of Mechanical Engineering, Kobe University, 1-1, Rokkodai, Nada, Kobe, Japan
}

\begin{abstract}
Measurements of the shape and dimensions of the pits and cracks formed in corrosion fatigue tests of a high-strength aluminium alloy, 7075-T651 were conducted by computed-tomography using ultra bright synchrotron radiation X-ray. Complex corrosion process could be observed and detail shape of corrosion pits could be identified. Sometimes, corrosion pit was formed under passive film, and those were not observed from the surface.
\end{abstract}

\section{Introduction}

The strength of metallic materials in corrosive environment is usually much lower than that in inert environment, and the stress enhances the corrosion damage because of the rupture of the passive film, which reduces the exposure of bare metal surface to the deleterious environment. In fatigue of metals in air, cracks are usually initiated from slip bands those are formed at the surface. In corrosive environment, the passive film is ruptured by the slip of grain, and then local cell is formed, where the bare metal face is anode and the passive film is cathode. As a result, a small hole, called the corrosion pit, is formed, and it gradually grows, finally cracks are initiated from the pits. Therefore, it is important to examine the formation and growth behavior of the corrosion pit to understand the corrosion fatigue damage.

Although the growth behavior of the corrosion pit in the corrosion fatigue process has been observed by optical microscopy, three dimensional shape of the pit could not be identified. Komai and his co-workers developed a stereo fractography technique by scanning electron microscopy (SEM) [1]. In this method, however, the interruption of the fatigue test is unavoidable, and a sample has to be observed in vacuum. They also conducted in-situ observation of the growth behavior of corrosion pit by scanning atomic force microscopy (AFM) in the corrosive environment [2]. Nakai and his co-workers conducted AFM observations of pits those were formed in corrosion fatigue [3, 4]. However, only the surfaces with roughness less than few $\mu \mathrm{m}$ can be observed by AFM, although the corrosion pit formed in corrosion fatigue grows up more than $10 \mu \mathrm{m}$ in depth. Therefore, only the initial stage of corrosion fatigue process could be studied by AFM.

High-strength aluminium alloy is a very useful material for components where high specific strength is required. In corrosive environment, however, the fatigue strength of the alloy is usually very low because of the formation of the corrosion pits. The shape of the pits depended on the microstructure, and they were very complicated [5]. Then it is usually difficult to determine the

\footnotetext{
a e-mail : nakai@mech.kobe-u.ac.jp
} 
Table 1. Chemical composition of 7075-T651 (mass\%).

\begin{tabular}{c|ccccccccc}
\hline Material & $\mathrm{Si}$ & $\mathrm{Fe}$ & $\mathrm{Mn}$ & $\mathrm{Mg}$ & $\mathrm{Zn}$ & $\mathrm{Ti}$ & $\mathrm{Cr}$ & $\mathrm{Cu}$ & $\mathrm{Al}$ \\
\hline $\mathrm{A}$ & $<0.01$ & 0.08 & $<0.01$ & 2.32 & 5.65 & 0.05 & 0.20 & 1.57 & bal. \\
$\mathrm{B}$ & 0.08 & 0.14 & 0.04 & 2.7 & 5.9 & 0.02 & 0.19 & 1.6 & bal. \\
$\mathrm{C}$ & 0.09 & 0.24 & 0.07 & 2.4 & 5.7 & 0.01 & 0.20 & 1.5 & bal. \\
\hline
\end{tabular}

stress concentration factor, local environment, and crack initiation site in the corrosion pit. The purpose of the present paper is to identify the shape of the corrosion pits three dimensionally and crack initiation site in a high-strength aluminium alloy under corrosion fatigue. Micro computedtomography using the ultra-bright synchrotron radiation X-ray (SR- $\mu \mathrm{CT}$ ) was employed for the observation. The authors have been applied the SR- $\mu \mathrm{CT}$ to the 3D measurement of inclusions and cracks in steels, and a titanium alloy [6-9].

Table 2 Mechanical properties of materials.

\begin{tabular}{c|ccc}
\hline Material & $\begin{array}{c}0.2 \% \text { proof stress } \\
(\mathrm{MPa})\end{array}$ & $\begin{array}{c}\text { Tensile strength } \\
(\mathrm{MPa})\end{array}$ & Elongation (\%) \\
\hline A & 510 & 567 & 11 \\
$\mathrm{~B}$ & 548 & 599 & 12 \\
$\mathrm{C}$ & 575 & 609 & 12 \\
\hline
\end{tabular}

\section{Experimental procedures}

The materials employed for the present study was a high-strength aluminium alloy, 7075-T651. The chemical compositions and mechanical properties of the alloys are shown in Tables 1 and 2, respectively. The shapes of the alloys when they were received were plates with thickness of $11 \mathrm{~mm}$ and $3.0 \mathrm{~mm}$ for Materials $\mathrm{A}$ and $\mathrm{B}$, respectively, and it was round bar with diameter of $10 \mathrm{~mm}$ for Material C. The shapes and dimensions of the specimens are shown in Figure 1. A computer controlled electro-dynamic test machines were employed for the fatigue tests, where cyclic bending was applied to Materials A and B, and cyclic axial-force to Material C. Fatigue tests were conducted in $3.0 \% \mathrm{NaCl}$ solution at a stress ratio, $R$, of -1 , with loading frequency of $30 \mathrm{~Hz}$ for Materials $\mathrm{A}$ and $\mathrm{C}$ and $20 \mathrm{~Hz}$ for Material B. The corrosion chambers are shown in Figure 2. It was made of silicone rubber tube for Material B, and heat shrinkage tube for Material C. The corrosion fatigue tests for Material A were conducted in our pervious study to observe formation of pits by AFM, but it was not employed for the present CT observation. The $S-N$ curves for Materials A and B are shown in Figure 4. The corrosion fatigue life of them is almost identical.

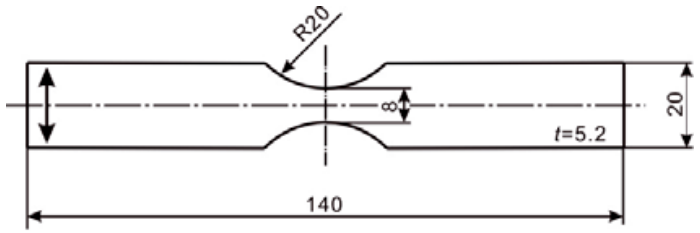

(a) Material A (Bending)

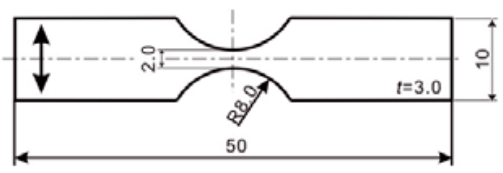

(b) Material B (Bending)

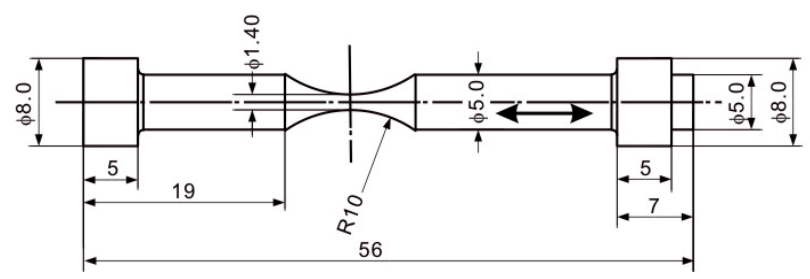

(c) Material C (Axial loading)

Fig.1 Shape and dimensions of specimens (in mm, Arrows indicate rolling direction). 


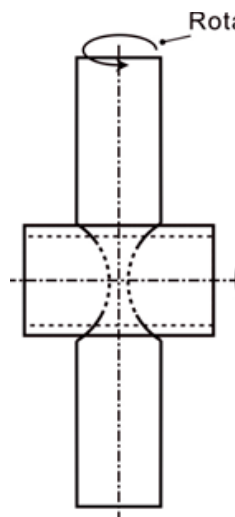

(a) Type I

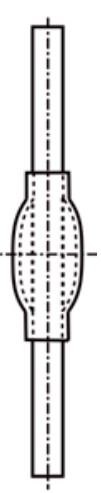

(b) Type II

Fig. 2 Corrosion cell for Material B.

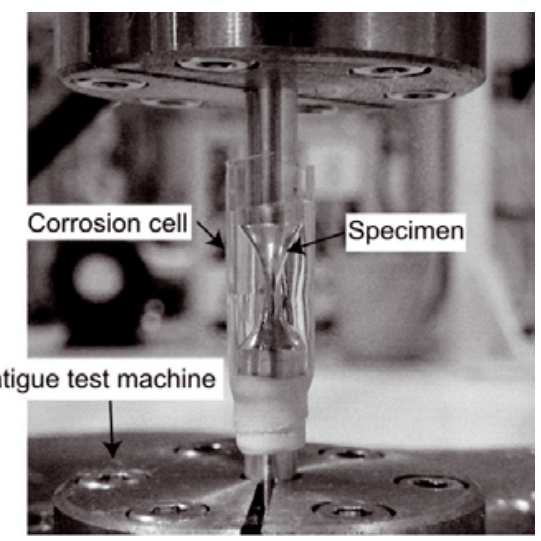

Fig. 3 Type III corrosion cell formaterial C.

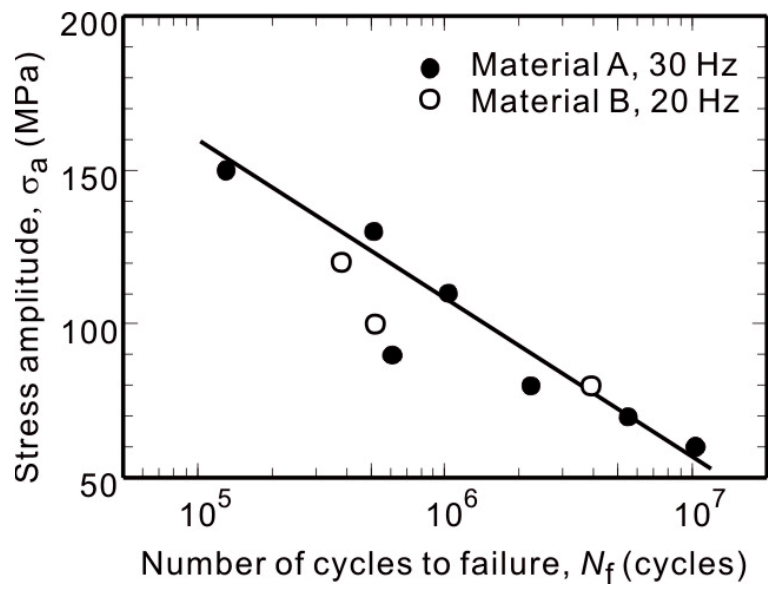

Fig. 4 S-N curve in $3 \% \mathrm{NaCl}$ solution.

SR- $\mu$ CT imaging was carried out at beam line, BL19B2, of SPring-8, which is the world's large synchrotron radiation facility. X-ray energy was adjusted to $28 \mathrm{keV}$ with silicon double-crystal monochromator. The distance between a bending magnet (X-ray source) and the specimen was about $100 \mathrm{~m}$. X-ray area detector was set by $150 \mathrm{~mm}$ behind the sample. The projection image of penetrated X-ray was observed by an X-ray area detector. The detector was composed of a beam monitor and cooled CCD camera. Transmitted X-ray is converted to visible light through a thin phosphor screen and projected to the CCD camera by an optical relay-lens. The size of the pixel in the transmitted projection image was $1.37 \mu \mathrm{m}$ for Material $\mathrm{B}$ or $0.70 \mu \mathrm{m}$ for Material C. For 3D reconstruction of Material B, a set of 600 radiographs of a sample were recorded over $180^{\circ}$ rotations, where each rotation angle was $0.3^{\circ}$. The angle was $0.5^{\circ}$ for 360 radiographs of Material C. Slice images were reconstructed from the series of projection images by filtered-back projection algorithm.

\section{Experimental results and discussion}

\subsection{Artifact generated by corrosion chamber}

For the CT imaging of aluminum alloy specimen, more than $1 \mathrm{~h}$ was needed to obtain data for 3D reconstruction because it took $10 \mathrm{~s}$ of X-ray exposure for recording every radiograph. To avoid the progress of corrosion during the data acquisition, the observation was carried out without immersing 


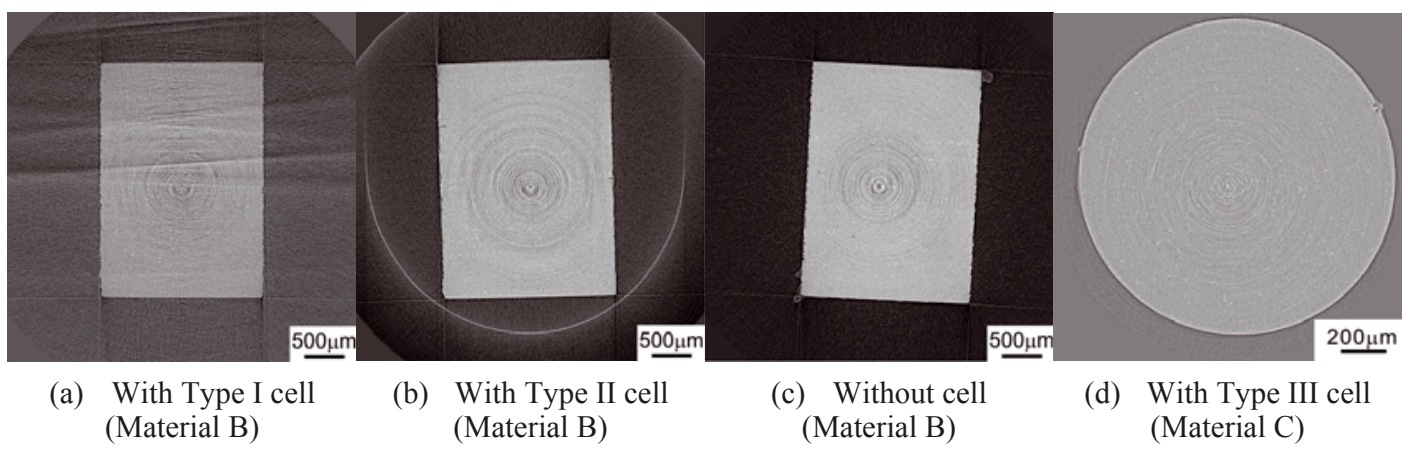

Fig. 5 Effect of corrosion cell on CT imaging.

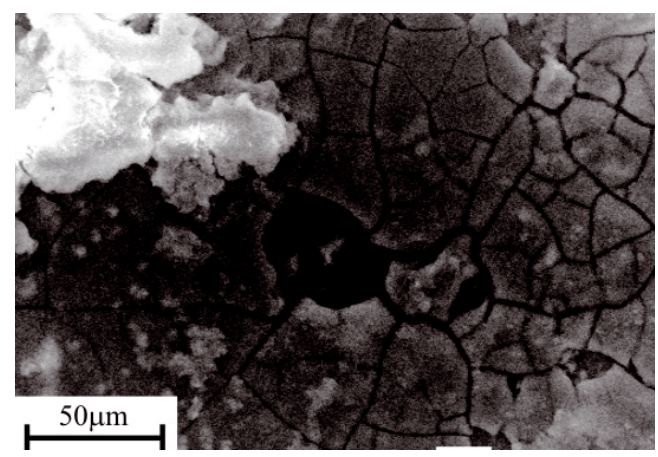

Fig. 6 SEM image of specimen surface $\left(\sigma_{\mathrm{a}}=80 \mathrm{MPa}, N_{\mathrm{f}}=4.97 \times 10^{6}\right)$.

sample in the solution. For examining how the existence of corrosion chamber affects the reconstruction image, three types of corrosion chamber were employed. The results are shown in Figure 5, where (a), (b), and (c) are images from the rectangular cross section sample (Material B), and (d) is that from the circular cross section sample (Material C).

In principle, it is necessary that the overall observation area, including the sample and the corrosion chamber, should be set in the recording area of CCD camera for CT imaging. Since large recording area results in the loss of the resolution for the imaging, only specimen observation area was set in the recording area. At first, we expected that the effect of corrosion chamber may be negligible because the X-ray absorption by silicone rubber is much smaller than that by aluminum alloy, and we tried Type I corrosion chamber, whose width is bigger than the recording area

The cross section image of CT with Type I and Type II chambers are shown in Figures 5 (a) and (b). For Type I chamber, artifact, which crosses the section of the sample, appears although the artifact exist only outside of the sample in Figure 5 (b) for Type II chamber. The difference between Types I and II chamber is that in X-ray penetration thickness of the chamber is almost constant for Type II chamber, and it is not for Type I chamber. The thickness of the silicon rubber changes discontinuously in Type I chamber as shown in Figure 5 (a). There still appear artifacts outside of the cross section of the sample as shown in Figure 5 (b) for Type II chamber although no artifact appears in Figure 5 (c), which was obtained without chamber. The elliptical shape of the cross section of the chamber may have brought the artifact because the penetration thickness of the silicone rubber is not exactly uniform. For Type III chamber, where both chamber and sample have circular cross section, no artifact is appeared as shown in Figure (d) despite only part of the chamber was in the record area.

In the cross section images, circumferential patterns, whose center agrees with the sample rotation center for CT, appeared. These patterns are also considered to be artifact. This kind of artifact must come from random noise of the measurement system, and could not be eliminated. 


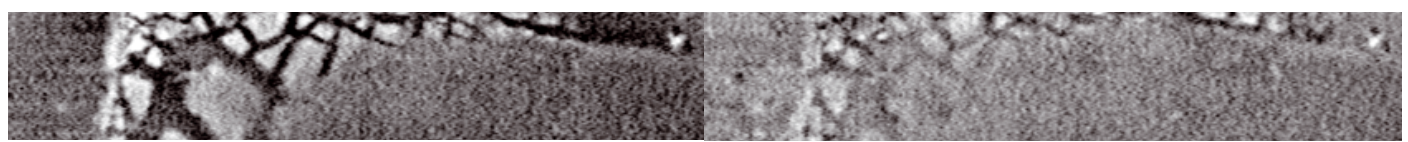

(a) $4.1 \mu \mathrm{m}$ above the interface

(b) $1.4 \mu \mathrm{m}$ above the interface

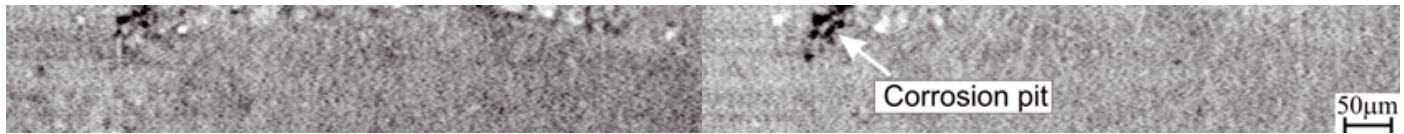

(c) At the interface

(d) $2.7 \mu \mathrm{m}$ below the interface

Fig. 7 CT images $\left(\sigma_{\mathrm{a}}=120 \mathrm{MPa}, N=3.5 \times 10^{5}\right.$ cycles $)$.

\subsection{Observations of the corrosion pit}

\subsubsection{Comparison of CT images with SEM images}

A SEM image of the surface of Material B in corrosion fatigue is shown in Figure 6. The surface is covered with a passive film, and the film is cracked and shows hexagonal pattern, where some part of the film is peeling off. An example of CT images of the same specimen are shown in Figure 7, where (a) and (b) is in a passive film, (c) is near the interface between passive film and base metal, and (d) is in base metal. Small cracks are also observed in the passive film layer observed by CT. It is important to note that the corrosion pits exist under the passive film, those were not found by the conventional microscopy. After $5 \times 10^{4}$ cycles from this observation, the passive film was peeled off and the pit could be observed by optical microscopy. In this alloy, successive formation and peeling off of the passive film was found.

\subsubsection{Three-dimensional shape of corrosion pit}

The CT image of corrosion pit was binarized and three dimensionally displayed in Figure 8 . This pit was formed from an inclusion and the depth of the pit was $10 \mu \mathrm{m}$.
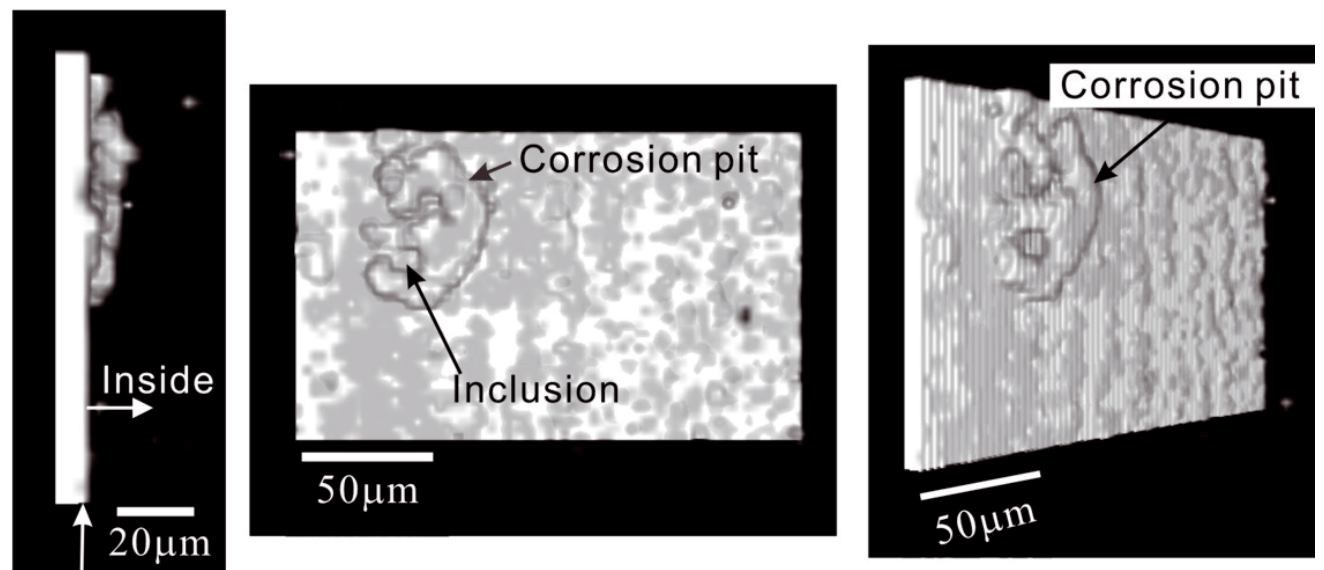

Surface

Fig. $8 \mathrm{CT}$ images of corrosion pit in Material $\mathrm{B}\left(\sigma_{\mathrm{a}}=120 \mathrm{MPa}, N=3.5 \times 10^{5}\right.$ cycles $)$. 


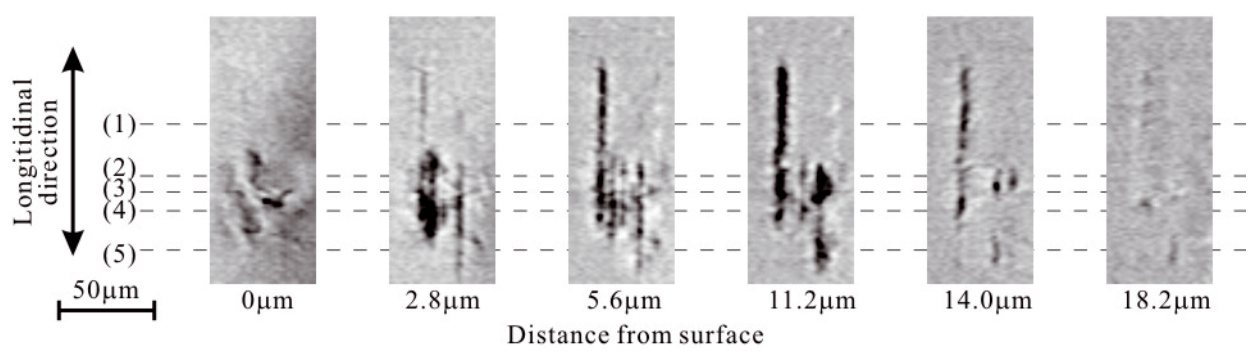

(a) In the circumferential section (parallel to the surface).

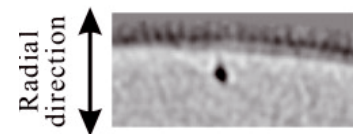

(1)

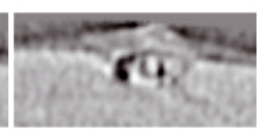

(2)

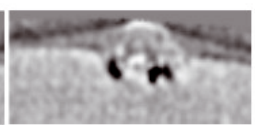

(3)

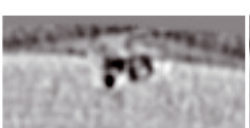

(4)

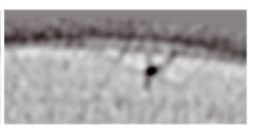

(5)

Longitudinal position shown in (a)

(b) In the transverse section.

Fig. $9 \mathrm{CT}$ images of Material C $\left(\sigma_{\mathrm{a}}=115 \mathrm{MPa}, N=4.9 \times 10^{5}\right.$ cycles $)$.

\subsubsection{Formation of corrosion pit}

Detail observations of corrosion pits were conducted by circular cross sectional specimen with diameter of $1.4 \mathrm{~mm}$ (Material C). Owing to the slight difference between chemical composition of Materials $\mathrm{B}$ and $\mathrm{C}$, the property of passive film is different, i.e., in Material $\mathrm{C}$, hexagonally cracking and peeling off of the passive film were not observed. A corrosion pit formed under stress amplitude of $115 \mathrm{MPa}$ at number of cycles, $N$, of $4.9 \times 10^{5}$ is indicated in Figures 9 and 10 , where Figure 9 shows the slice image, and Figure 10 is a three dimensional demonstration of the binarized image. In Figure 9, the corrosion pit was extends to the longitudinal direction (rolling direction). Since the pit was covered with passive film on the surface, it may have not be observed from the surface observation by conventional microscopies, but surface at the pit was swelling up. Such swelling has been recognized in the AFM observation of the martensitic stainless steel [3, 4]. Inside of the material, this pit extended like root of plants. It suggests that anodic dissolution occurred along axially elongated inclusions or grain boundary.

Another example of corrosion pit is shown in Figure 11. The shape of the corroded area is similar to that shown in Figures 9 and 10, and the swelling on the surface is more remarkable. These findings indicate that the corrosion speed was high where inclusions reached to the surface.

\subsubsection{Growth of corrosion pit}

Growth behavior of corrosion pit, shown in Figure 9, is displayed in Figures 12 and 13. The increase of corroded area and depth with number of cycles (or with time) could be measured from Figures 10, 12 and 13, and the shape of the corrosion pit shown in Figure 13 is similar to that observed by Wei and his co-workers [5].
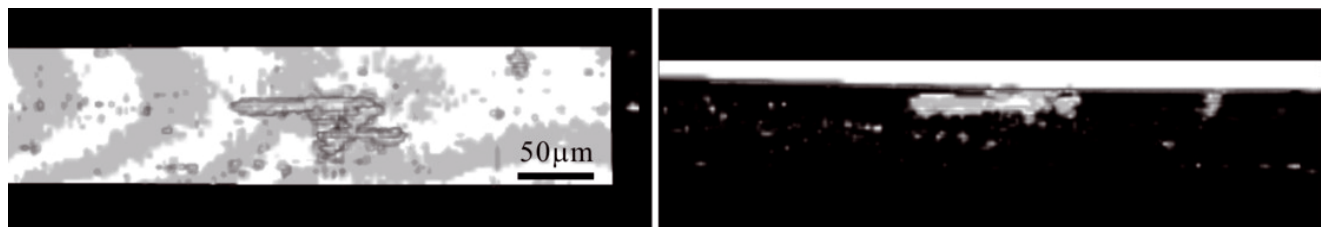

Fig. $103 \mathrm{D}$ image of inclusions (Material C, $\sigma_{\mathrm{a}}=115 \mathrm{MPa}, N=4.9 \times 10^{5}$ cycles). 

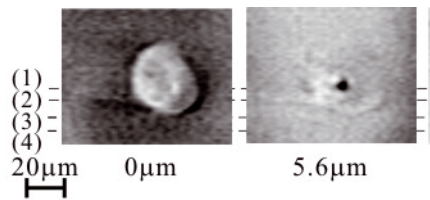

$5.6 \mu \mathrm{m}$

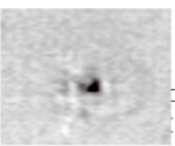

$8.4 \mu \mathrm{m}$

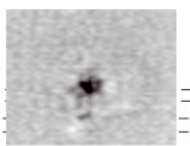

$11.2 \mu \mathrm{m}$

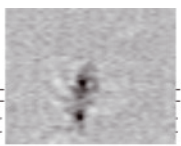

$15.4 \mu \mathrm{m}$

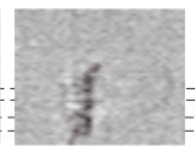

$18.2 \mu \mathrm{m}$

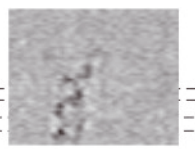

$22.4 \mu \mathrm{m}$

(a) In the circumferential section (parallel to the surface).

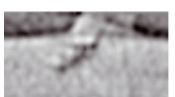

$\stackrel{20 \mu \mathrm{m}}{\longmapsto}$

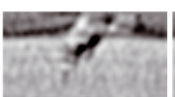

(1)
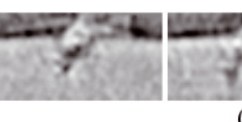

(2)

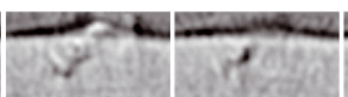

(3)

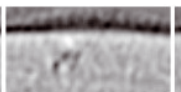

Longitudinal position shown in (a)

(b) In the transverse section.

Fig. $11 \mathrm{CT}$ images of Material $\mathrm{C}\left(\sigma_{\mathrm{a}}=115 \mathrm{MPa}, N=4.9 \times 10^{5}\right.$ cycles $)$.

\subsubsection{Initiation of crack}

Initiation process of cracks from corrosion pits shown in Figure 13 is indicated in Figure 14, where CT images of corrosion pit at the crack initiation site before and after the crack initiation is presented. From CT images of specimen surface ( $x-z$ plane), which is shown in Figure 14, indicate that crack was not formed from the largest corrosion pit at the surface. Otherwise, it was formed from large corroded area which was not necessarily deep. In the section image ( $y-z$ plane) which is perpendicular on the surface, as shown in Figure 14, the corroded region exists inside of the material ahead of the corrosion pit, and a crack initiated at the deepest point of the corroded area, whose depth was $40 \mu \mathrm{m}$, although the depth of corrosion pit was $12 \mu \mathrm{m}$.
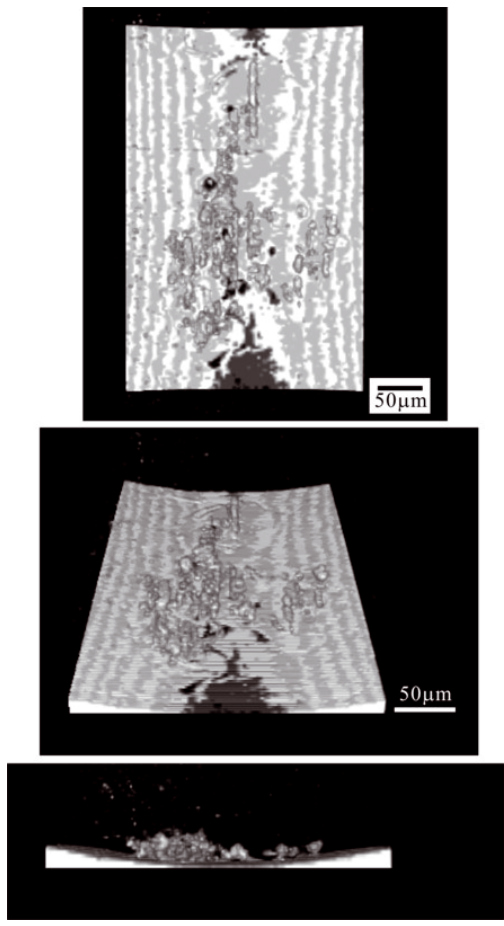

Fig. 12 Corrosion pit $\left(N=5.94 \times 10^{5}\right.$ cycles $)$.

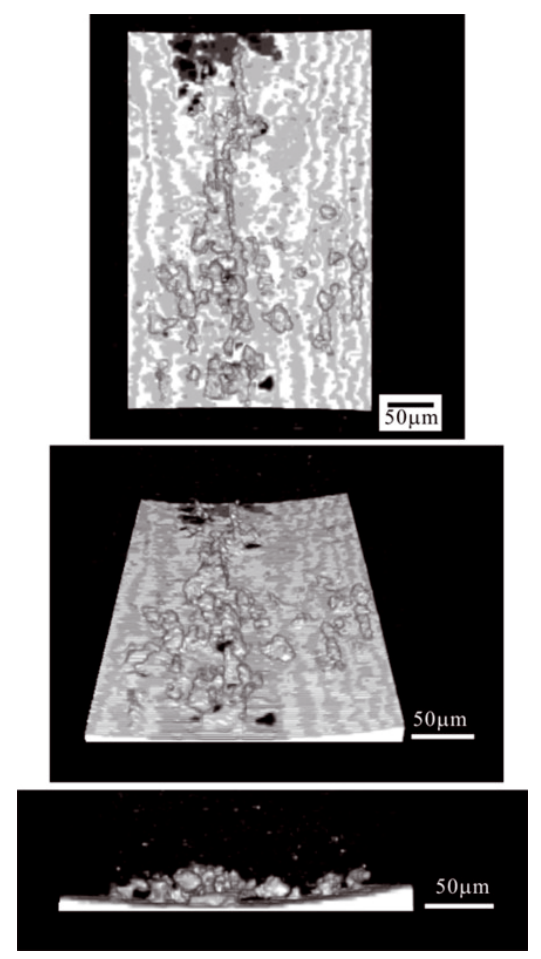

Fig. 13 Corrosion pit $\left(N=1.24 \times 10^{6}\right.$ cycles $)$. 


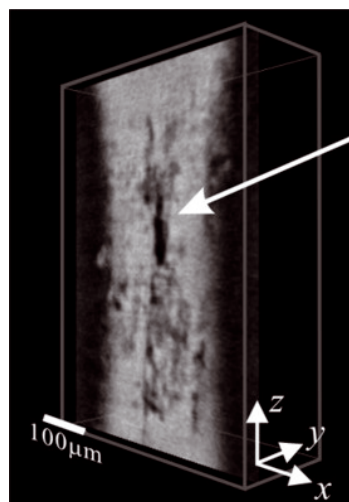

Surface

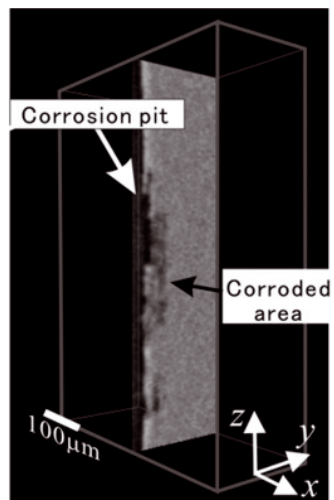

Cross-section

(a) $N=1.24 \times 10^{6}$ cycles

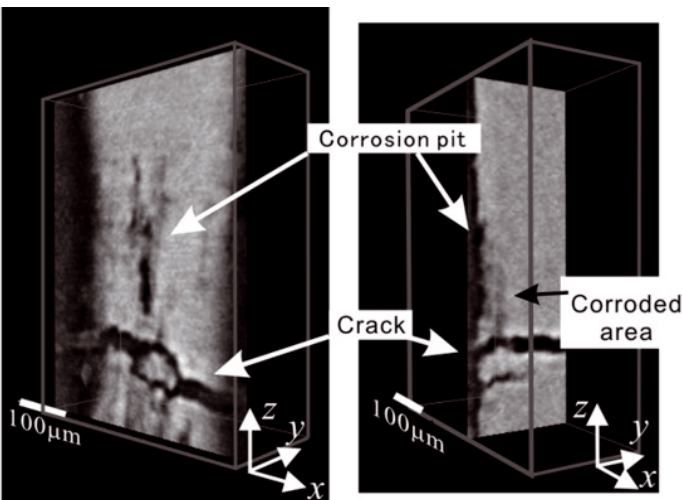

Specimen surface
Cross-section

(b) $N_{\mathrm{f}}=1.25 \times 10^{6}$ cycles

Fig. 14 Crack initiation from corrosion pit.

\section{Conclusions}

Measurements of the shape and dimensions of the pits and cracks formed in corrosion fatigue tests of a high-strength aluminium alloy, 7075-T651 were conducted by computed-tomography using ultra bright synchrotron radiation X-ray. The results obtained are as follows.

(1) Complicated corrosion phenomenon could be observed by computed tomography imaging using ultra-bright synchrotron radiation, and detail shape of corrosion pits can be identified. The effect of metal microstructure on the corrosion fatigue process can also be evaluated.

(2) Sometimes, corrosion pit was formed under passive film, and those were not observed from the surface.

\section{Acknowledgment}

The authors gratefully acknowledge the approval of the Japan Synchrotron Radiation Research Institute (JASRI) to use beam line (BL19B2) in SPrin-8 (Project number: 2008A1886). The authors also express their appreciation to Dr. K. Kajiwara for his technical support.

\section{References}

1. K. Komai, J. Kikuchi, Stereo Fractography, Yokendo, p.48 (Tokyo, 1996)

2. K. Komai, K. Minoshima, M. Itoh, J. Soc. Mat. Sci., Japan, 43, 336 (1994)

3. Y. Nakai, S. Fujiwara, T. Ogawa, Y. Shimizu, Mat. Sci. Res. Int., STP1, pp.101-106 (2001)

4. Y. Nakai, Y. Shimizu, S. Fujiwara, T. Ogawa, Proc. 10th Int. Conf. on Fracture, CD-ROM, 101 (2001)

5. R. P. Wei, D. G. Harlow, Proc. Fatigue 99, 2197 (1999)

6. Y. Nakai, D. Shiozawa, Y. Morikage, T. Kurimura, H. Tanaka, H. Okado, T. Miyashita, Proc. 4th Int. Conf. on Very High Cycle Fatigue, 67 (TMS, Warendale, Pennsylvania, 2007).

7. D. Shiozawa, Y. Nakai, T. Kurimura, K. Kajiwara, Proc. 12th Int. Conf. On Fracture, CD-ROM (2009)

8. D. Shiozawa, Y. Nakai, Y. Morikage, H. Tanaka, H. Okado, and T. Miyashita, Trans. JSME, 72, $1846(2006)$

9. D. Shiozawa, Y. Nakai, T. Kurimura,Y. Morikage, H. Tanaka, H. Okado, T.Miyashita, K. Kajiwara, J. Soc. Mat. Sci., Japan, 56, 951 (2007) 